\title{
FILMES COM TEMÁTICA HISTÓRICA PODEM SER VISTOS COMO HISTÓRIA PÚBLICA?
}

\section{HISTORICAL MOVIE CAN BE CONSIDERED A KIND OF PUBLIC HISTORY?}

\author{
Vitória Azevedo da Fonseca ${ }^{27}$
}

\begin{abstract}
The present text propose, considering a differentiation between public history produced by historians who understand other midias and, on the other hand, analyzes of possible public histories produced by non historians, this text propose two possible approximations betwen public history and historical films. First, based on Robert Rosenstone who think the historical film as a writing of the past, analyzes what histories tell in a movie considering relationships whith an tradition and second, thinkhing about possibilities of partnerships between filmmakers and historians in the script and synopse.
\end{abstract}

\section{RESUMO}

A partir de artigos sobre o "fazer" história pública, considerando uma diferenciação entre a história pública produzida por historiadores que dominam outras linguagens e as análises de possíveis histórias públicas produzidas à revelia de historiadores, propomos situar duas possíveis aproximações com filmes históricos. Primeiro, tomando por base Robert Rosenstone, pensar o filme histórico como escrita do passado, produzida à revelia dos historiadores, mas que, no entanto, pode ser inserido em um contexto maior de abordagem da temática que propõe a partir da análise do roteiro cinematográfico e, segundo, pensar em possibilidades de parcerias entre cineastas e historiadores na atuação deste último na elaboração de argumentos e roteiros para filmes.

\section{KEYWORDS}

Historical moveis; public history; sare authority.

\section{PALAVRAS-CHAVE}

Filme histórico; história pública; autoridade compartilhada.

\section{Introdução}

Sem dúvida os filmes, ao longo de décadas, em diferentes países, atuaram como produtos culturais importantes em elaborações e reelaborações de culturas históricas, difundindo, criando ou desmontando imagens, percepções, sentimentos sobre a experiência do homem no tempo. Cinemas criando culturas e filmes como fontes históricas tem sido investimentos importantes das pesquisas historiográficas sobre cinema e história, já com

27 Doutora em História, Universidade Federal Fluminense/Universidade Federal dos Vales do Jequitinhonha e Mucuri: vitória.azevedo@gmail.com 
larga produção acadêmica. Os debates em torno da história pública poderiam alterar percepções e debates já em desenvolvimento nesta área? Poderiam sugerir novas abordagens e práticas?

O termo "história pública", recentemente difundido no Brasil, usado em outros países desde a década de 1970 e, frequentemente associado ao que se fazia sob a denominação de história oral, ganha, ao se configurar como campo de pesquisa, seja em torno da institucionalização a partir da criação da Rede Brasileira de História Pública (RBHP), em 2012, da organização do Simpósio Internacional de História Pública (1ºm São Paulo, 2012; $2^{\circ}$ no Rio de Janeiro, em 2014, o 3º, em Cariri, em 2016 e o $4^{\circ}$, em 2018, em São Paulo), seja através da disseminação de textos, dossiês, cursos, uma dimensão ampla e polissêmica que abarca diversas possibilidades de interpretações, dentro de alguns limites. A constituição de um campo de diálogos, a partir de determinados lugares de fala, vem delimitando as dimensões da história pública no Brasil. O ser visto e ouvido em um espaço de compartilhamento de saberes, no que diz respeito ao tema, se consolida nas publicações de livros e artigos que, em algum sentido, travam diálogos entre "iguais".

Conforme a apresentação do livro História Pública no Brasil sentidos $e$ itinerários, os autores Ana Maria Mauad, Juniele Almeida e Ricardo Santhiago, refletem sobre os usos e as possibilidades do termo "história pública" na atualidade.

Seguindo a fórmula sob a qual o termo public history (com suas diversas traduções se consagrou, tendemos em um primeiro momento a compreender a história pública como uma prática eminentemente voltada àquela 'divulgação histórica' (...) e, de fato, a produção de materiais para circulação e consumo de uma audiência mais ampla do que nossos pares acadêmicos consiste em uma de suas modalidades mais nobres. Entretanto, os sentidos atribuídos à história pública contemplam também os engajamentos (muitas vezes conflituosos, mas ainda assim instigantes) entre o historiador e a produção acadêmica, de um lado, e os diletantes e seus trabalhos que respondem a demandas próximas e imediatas, de outro. Aqui, a história pública age no reconhecimento da legitimidade desses trabalhos tidos como 'amadores', bem como no delineamento das diferenças entre as duas práticas; ou então em uma atuação colaborativa, na qual os diferentes agentes produtores trabalham dialogicamente (MAUAD, ALMEIDA, SANTHIAGO, 2016, p.12). 
Conforme os autores citados, em um viés das preocupações em torno da chamada história pública, está inserida uma possibilidade colaborativa entre o que se produz no contexto acadêmico em termos de conhecimento histórico e a produção de conhecimento sobre o passado fora deste contexto. A multiplicidade de sentidos da história pública traz, assim, a ideia da preocupação com o rompimento de barreiras entre o espaço acadêmico de produção historiográfica e o contato com um público não acadêmico.

Santhiago elenca o que chama de "três instâncias" da história pública: o fazer, o pensar e o campo de reflexão. No primeiro caso, estão inseridos aqueles que efetivamente fazem história pública, em suas mais diversas experiências, tendências e consequências; no segundo e terceiros casos, atuações ligadas às universidades e produções acadêmicas.

Quem são alguns daqueles que "fazem" histórias públicas? Respondendo a esta pergunta, Schmidt (2018) remete às experiências de egressos dos cursos de História que, optando por caminhos alternativos aos já consagrados ensino/pesquisa, passaram a atuar em diversos espaços a partir de suas formações em História. Com a emergência da "história pública" foi possível atribuir nome ao que já vinha sendo feito por estes profissionais.

Com isso, também emergiu um novo sujeito: o historiador público, e não mais o historiador 'diferentão' que, ao contrário da maioria de seus pares, não atua como professor ou pesquisador strictu sensus mas em espaços públicos e privados variados, como museus, arquivos, memoriais e secretarias de turismo; ou gerenciando websites e blogs; ou assessorando produtoras de cinema e editoras. Sujeito esse que busca espaço, voz e, sobretudo, reconhecimento profissional (SCHMIDT, 2018, p.18).

Essa figura do historiador, atuando em diferentes espaços, reinventando o fazer historiográfico em mídias diferentes das recorrentes é identificado, neste caso, com aquele que faz história pública. Mas, será que o único que produz história pública é o historiador “deslocado"? O que caracteriza a história pública?

No livro Que história pública queremos, os diversos autores, convidados a responderem ao chamado trazem dimensões variadas para a pergunta. Em alguns, emerge a compreensão de que é pública a história feita pelo historiador difundida em audiências maiores, em linguagens acessíveis; ou, aquela feita de maneira compartilhada em métodos e produtos; partindo da ciência de referência. Em outros casos, história pública é aquela 
construída a partir de outros agentes, variados, que emergem da grande circulação de informações e imagens que, de alguma maneira, transformam/constroem realidades; ou ainda aquelas produções que problematizam o passado/presente em, principalmente, produtos culturais e artísticos. O fazer, do primeiro caso, emerge como possibilidade desejável no campo historiográfico na construção da própria legitimidade deste campo se considerarmos as preocupações trazidas por Jörn Rüsen e a didática da história. O fazer do segundo caso, emerge, algumas vezes, como análise do trabalho de outros e possibilidades de compreensão dessa história produzida sem chancelas, em espaços e mídias variados.

Assim, as possibilidades diversas do fazer história pública e a ambígua relação entre o historiador e as histórias públicas, seja como promotor ou como analista, é interessante para pensar o que estou propondo: a viabilidade da produção de história pública audiovisual a partir do compartilhamento de saberes em produções conjuntas.

\section{Histórias compartilhadas: quem faz a história pública?}

Compartilhar é uma ideia importante utilizada por Frisch na expressão “autoridade compartilhada" construída a partir de suas experiências com história oral, fundamental para construir as bases das suas reflexões sobre história pública. O debate em torno da "autoridade compartilhada" e de possíveis incompreensões da expressão trazem problemáticas importantes. Segundo Frisch, a expressão sugere "que na natureza da história oral e da história pública nós não somos a única autoridade, os únicos intérpretes, os únicos autores-historiadores" (FRISCH, 2016, p.62).

Neste sentido, a compreensão de história pública se solidifica em torno da ideia de "autoridade compartilhada" na qual historiadores e seus métodos de pesquisa (de história oral) encontram produtores de memórias e narrativas ("suposto público") num processo de construção dialógica de histórias, as quais são compartilhadas para uma comunidade não acadêmica. Os princípios dos processos e produtos, decorrentes de práticas de história oral, confluem na delimitação dos espaços de construção da história pública no Brasil.

Considerando a ideia da autoridade compartilhada, quem são os sujeitos do fazer essas histórias? Como seria possível um diálogo compartilhado? Almeida defende o estabelecimento de pontes "entre o saber acadêmico e o trabalho não científico (trabalho de 
memória realizado pelos próprios integrantes dos movimentos)” (ALMEIDA, 2016, p.52) também preconiza alguns limites: “ a não-supressão da ciência histórica em favor da história pública, reforçando um desejo mútuo de diálogo com as práticas e reflexões não acadêmicas compromissadas com a história" (ALMEIDA, 2016, p.53. grifo nosso). Esses limites, não muito claros, deixa alguns questionamentos: existe aí uma oposição entre uma história pública e a ciência histórica, estabelecendo, com isso, uma espécie de fronteira entre ambas. Ou seja, ainda existe algo feito por "nós" e algo feito por "eles"; e, o questionamento sobre o que seriam práticas compromissadas com a "história". Essa afirmação deixa dúvida sobre o limite da defesa de um suposto diálogo na construção de uma história compartilhada quando este é feito a partir de parâmetros estabelecidos apenas por uma das partes.

Renata Schittino (2016), questionando o conceito "público" a partir de referências gregas e romanas, passando por Hannat Arendt e Habermas, aponta para possibilidades da acepção do vocábulo. Tomando como referência Hannah Arendt, a autora traz a ideia do público como espaço do ser visto e ouvido, na construção de um espaço comum, de visibilidade coletiva, na construção de sentidos compartilhados por um número maior de pessoas e, portanto, da construção de uma existência. Por outro lado, seguindo Habermas, uma possibilidade seria pensar no papel do historiador como mediador na popularização do conhecimento histórico. Entre pensar a história pública como espaço de compartilhamento e pensar a história pública como espaço de mediação, ela propõe a história pública como um espaço de compartilhamento e não de popularização de saberes acadêmicos. Assim, esta seria uma “...forma específica - uma dentre outras com as quais pretende conviver e conversar - como entre iguais e diferentes num mundo comum". (SCHITTINO, 2016, p.45)

\footnotetext{
...o compartilhamento nos deixa ver que a questão da história pública é menos a questão de fronteira - de demarcação de fronteira e mais uma possibilidade de olharmos para os lados, para cima, para baixo e assumirmos esse mundo comum como um diálogo possível (SCHITTINO, 2016, p.46).
}

Qual o papel do historiador na construção da história pública? A ideia de uma história pública como saber historiográfico popularizado, ou a ser popularizado, a partir de práticas e produtos está presente em diversas reflexões presentes no livro Que história pública queremos? 
$\mathrm{Na}$ tentativa de relacionar ensino de história e história pública, por exemplo, a ênfase recai na formação e atuação do professor, principalmente, como um "mediador" de história pública. "Durante o processo de ensino, o professor realiza operações que confluem para a divulgação, difusão e circulação do conhecimento histórico." (FERREIRA, 2018, p.34). Esse docente, mediador, ou aquele que realiza uma "transposição didática", conceito amplamente discutido/questionado nos debates na área de ensino de História, teria o papel de corrigir compreensões e mediar aprendizados. "O ensino no viés da história pública é um trabalho ampliado e de contínua mediação. A esperança é que os profissionais e estudantes não sejam seduzidos pelo 'ouro de tolo' mercadológico, que imbui a ideia de produto com impacto de marketing" (FERREIRA, 2018, p.38).

Marieta Ferreira, ao responder sobre as relações entre professores de história e a história pública, a partir do ProfHistória (Mestrado Profissional de Ensino de História), traz essa dimensão do professor de história, no âmbito do ensino, como “...responsável por traduzir o conhecimento acadêmico da área e, como auxílio do livro didático, estabelecer os parâmetros básicos do que se entende por história, visando o público geral em formação" (FERREIRA, 2018b, p.50). O professor, às vezes entendido como historiador, às vezes entendido como repassador de conteúdos, é eleito, justamente, como figura importante no processo de criação de espaços públicos de histórias compartilhadas ${ }^{28}$.

Um espaço importante de compartilhamento e construção de passados é o espaço da Web, e as mídias digitais. Carvalho (2018), desenvolvendo reflexões sobre a autoridade do historiador na internet, traz a questão da possibilidade ampliada de geradores de discursos promovida pela Web e a difusão de informações, acessíveis a um grande público, que supostamente pulveriza informações sobre o passado, eclipsando o papel do historiador. Os desafios do historiador, neste sentido, seria ocupar um espaço de poder no mundo virtual que envolve ganhar legitimidade dominando a "linguagem" e atingindo grande número de likes e views. Carvalho atribui a dificuldade do historiador em ocupar esse espaço em função da ausência de habilitação na lida com diferentes linguagens/ferramentas de comunicação.

\footnotetext{
${ }^{28}$ Ressaltamos aqui que as relações possíveis entre ensino de História e história pública não passam somente pela atuação do docente, no espaço escolar.
} 
Algumas iniciativas de incorporação dessas linguagens na formação de historiadores se fazem presentes, por exemplo, em iniciativas como as descritas por Rodrigues, ocorridas na UDESC (Universidade do Estado de Santa Catarina) onde foram criadas disciplinas de caráter prático que possibilitam “...iniciar os aprendizes de historiador (...) a montar um pequeno documentário em vídeo, a construir um roteiro de programa para rádio e/ou televisão, a dar apoio técnico na organização de acervos e exposições" (RODRIGUES, 2018, p.281). Outra iniciativa no mesmo curso diz respeito à inserção de disciplina que promove reflexões e exercícios sobre outras formas de escritas historiográficas:

Os discentes fazem exercício de escrita de história para jornais, blogs e roteiros turísticos; são iniciados na linguagem da ficção histórica, da produção de biografias e autobiografias, fazem exercícios de transposição de trabalhos acadêmicos para textos didáticos, entre outras modalidades (RODRIGUES, 2018, p.282).

Os espaços outros a serem ocupados pelos historiadores estão sendo a partir de iniciativas, como por exemplo, do projeto Passado Presente, que traz problemáticas que serão cada vez mais recorrentes nesse processo de compartilhamentos de saberes. "Como não estamos escrevendo livros ou artigos, mas conteúdo digital e placas turísticas, precisamos aprender a escrever de maneira pouco usual na Academia." (MATTOS, GRINBERG e ABREU, 2018, p.234. Grifo meu).

Essas iniciativas descrevem atuações de historiadores como "mediadores" no espaço público. No entanto, além dessas histórias produzidas por historiadores, existiriam outras histórias públicas? Outros autores apontam para uma resposta positiva indicando que não é apenas o historiador quem faz história pública. Esta foi e continuará sendo feita à sua revelia.

A mobilização da experiência histórica para problematizar o presente, nos palcos da ditadura civil-militar, a partir da obra de Chico Buarque, é tomado por Hermeto (2018), por exemplo, como um exercício de história pública. Ao envolver uma parcela da população em debates em torno das obras Ópera do Malandro, Calabar e Gota d'água, os palcos se tornam lugares de história pública. 
Associando à discussão sobre as noções de público, trazidas por Schittino (2018), as considerações de Mauad problematiza a dimensão da fotografia pública numa compreensão não da autoridade compartilhada, processo e produto, mas da sua circulação, documentando e construindo realidades. "Assim, é pública não somente a fotografia publicada, mas aquela que se refere ao espaço público como tema e que tem no espaço público o seu lugar de referência política” (MAUAD, 2018, p.129).

A fotografia pública está estreitamente relacionada às configurações da memória social ao longo do século XX. Quer documentando de forma independente os acontecimentos sociais, registrando a ação dos governos ou reconfigurando-se nos mundos da arte, a prática fotográfica criou uma série de imagens que pavimentam o espaço público visual contemporâneo. (MAUAD, 2018, p.128).

Em uma direção semelhante, Meneses aponta para a produção de uma história pública a partir do monopólio de grupos de comunicação e a construção de visões do passado por meio de suas enunciações. Ela chama a atenção para esta dinâmica: “...uma visão unilateral sobre os usos do passado pode institucionalizar, em longo prazo, versões conservadoras da História, endossadas pelo poder econômico de distribuição da informação" (MENESES, 2018, p.186).

No âmbito dos espaços museais e similares, os debates em torno do patrimônio constroem passados que hoje podem ser associados à construção de histórias públicas. Patrimônio como história pública, argumenta Meneses (2018b), se justifica em função, não da mediação do historiador, como ponto de partida, mas, na circulação fora do campo acadêmico.

Os processos interpretativos do patrimônio histórico-cultural escaparam das mãos de acadêmicos e deixaram de ser um exercício da tradição da cultura erudita. Passaram a objetivar a construção de produtos para serem lidos, fruídos e interpretados por uma gama maior de 'consumidores de cultura'. Têm, assim, sido fundamentados em etapas que vão do inventário de bens e de valores à construção de linguagens museais, imagéticas e informativas, que apresentam o bem como um produto para a compreensão e a fruição prazerosa (MENESES, 2018b, p.70). 
Apesar do autor pontuar que a História daria o escopo fundamental, podemos indicar que tanto a educação museal, a educação patrimonial e debates em torno de museus e patrimônios vem sendo desenvolvidas ao largo das discussões historiográficas. Para Knauss, "...pode-se considerar que os museus enfrentam dilemas próximos dos da historiografia acadêmica, que se confrontou com o movimento da história pública" (KNAUSS, 2018, p.144). O autor aproxima as duas áreas em termos de desafios e objetivos, pontuando a distinção entre elas.

...os museus também enfrentam na atualidade os desafios de se dirigirem para o
seu público em busca de conquistar novas audiências. Com frequência, fazem uso
de estratégias de mobilização social para construir com seu público a interpretação
e a leitura de seus acervos e coleções, num movimento colaborativo de
reconhecimento de autoridade compartilhada" (KNAUSS, 2018, p.145).

História pública mediada pelos historiadores, historiadores emprestando-se de outras linguagens para comunicar-se com seu público, histórias produzidas à revelia dos historiadores, desafios de construir autoridades compartilhadas, são alguns dos problemas que compõem o universo em torno dos debates da "história pública" na atualidade. E, de que maneira algumas problemáticas em torno da relação entre Cinema e História poderiam se encontrar com os debates sobre história pública?

Em um sentido, pelo viés da história pública produzida a despeito do historiador, filmes podem produzir histórias públicas assim como os meios de comunicação e as fotografias. Por outro lado, a linguagem cinematográfica, da qual alguns historiadores tentam se apropriar, também pode ser um meio de produção de história pública mediada por historiadores. No entanto, há uma terceira possibilidade: a promoção de diálogos e compartilhamento de saberes na confluência entre cinema e história enquanto tradições de formas de pensar e formas de fazer.

\section{Filme histórico: de fonte histórica à história pública}

Marc Ferro, grande referência quando o assunto é cinema e história, historiador francês que, na década de 1970 trouxe os filmes para as análises historiográficas, escreveu a seguinte frase: “...os filmes sobre o passado, as reconstituições históricas são incapazes de ultrapassar o testemunho sobre o presente" (FERRO, 1992, p.117). A briga travada por Ferro 
estava na arena da legitimidade das "novidades", e, dentre elas, a legitimidade das "novas fontes" e "novas abordagens" trazidas pela "Nova História". O cinema, até então, na França, não era tomado como fonte histórica legítima. O medo do fascínio pelo cinema assombrava. Depois de argumentar os motivos pelos quais o cinema, assim como outras manifestações culturais, não se transformou em fonte para o historiador, Ferro denuncia: "Cinquenta anos se passaram. A história se transformou e o filme continua na porta do laboratório" (FERRO, 1992, p.84). O cinema continuava não sendo eleito como fonte histórica nas análises historiográficas.

Mas Marc Ferro triunfa em sua batalha. Demonstra, e instiga a outros historiadores, que imagens em movimento podem ser matéria prima do fazer historiográfico. Um filme pode ser fonte histórica. "Um filme testemunha" (FERRO, 1992, p.85), defende Ferro. "A câmera revela seu funcionamento real, diz mais sobre cada um do que seria desejável de se mostrar. Ela desvenda o segredo, apresenta o avesso de uma sociedade, seus lapsos" (FERRO, 1992, p.86). Durante muito tempo, pensar em cinema e história era pensar em Marc Ferro, no filme como testemunho de seu presente, na análise em busca dos "lapsos" dos realizadores, no filme como "uma contra-análise da sociedade".

Marc Ferro abre um caminho possível: a dos filmes como fontes históricas testemunhos de seu tempo. Uma luta travada em um tempo e espaço importantes na legitimação do cinema nas arenas historiográficas. No entanto, este não é o único caminho. O próprio Ferro, ao questionar, em outro texto, se é possível uma "escritura fílmica do passado" aponta para outras possibilidades na relação cinema e história.

No livro “Hacer historia com imagenes", de 2014, Robert Rosenstone, após situar as diferentes abordagens nas análises de filmes históricos, defende o filme histórico como forma de pensamento. Assim sendo, procura analisa-los a partir daquilo que o filme propõe como pensamento sobre o passado apesar da tendência, conforme aponta, das análises buscarem mais o presente nos filmes.

Esse tipo de leitura - que vê as obras como se não tratasse do passado a não ser o que está acontecendo no presente - é uma das abordagens mais comuns em relação ao filme histórico. Isso implica de maneira tácita que enquanto os filmes históricos somente reconfiguram o passado do ponto de vista dos conflitos e inquietudes do presente sobre a 
guerra, os movimentos sociais, os indivíduos, as ideologias. A história mais tradicional, quer dizer, a história escrita pelos acadêmicos, faz algo diferente, algo que escapa da influência do presente e se centra unicamente no passado" (ROSENSTONE, 2014, paginação irregular).

Esta prática, defende Rosenstone, é calcada na mistificação da história acadêmica. No entanto, qualquer historiador tem consciência, ou deveria ter, da historicidade de sua obra, da presença do presente em suas abordagens. Nesse sentido, o presente marca qualquer manifestação humana. "Como a história escrita, o filme histórico é também (independente do que reflete sobre o presente) uma maneira de pensar em acontecimentos e personagens do passado e lhes dar um sentido no presente" (ROSENSTONE, 2014, paginação irregular).

Os historiadores acadêmicos, nos diz Rosenstone, se opõem a considerar como "história" em função das ficcionalidades e invenções dos filmes, bem como as estratégias de convencimento de um filme. "Supõe-se que estes ingredientes nos induzem a sentir algo sobre o passado, mas a tendência é temer que estes mesmos elementos também nos impeçam de pensar ou refletir sobre o que acontece na tela." (ROSENSTONE, 2014, paginação irregular). Apesar das ressalvas, o filme histórico constrói passados.

O filme histórico, sem dúvida, envolve historiar. É uma forma de pensamento, uma maneira de pensar e colocar questões sobre o passado necessariamente diferente da história escrita. É verdade que nunca poderá ser tão fiel aos detalhes factuais do passado como o estudo acadêmico pelas razões que já defendi em outros trabalhos, em resumo, em função da câmera exigir detalhes mais específicos que vai além do que qualquer historiador possa conhecer, além disso, as artes dramáticas requerem que uma história tenha princípio meio e fim, assim como um arco de desenvolvimento com personagens e situações que mudam ao longo da obra. Mas, devemos lembrar que a história acadêmica é também uma forma de contar histórias, mas com exigências diferentes das dos filmes. O que o papel à tela é o fato de que ambos envolve usar informações para pensar em personagens e acontecimentos do passado, dando-lhes significados. Em poucas palavras, ambos são maneiras de historiar.” (ROSENSTONE, 2014, paginação irregular).

Considerando filmes históricos como formas de historiar, Rosenstone convida os historiadores a repensarem este produto a partir de uma compreensão do mesmo como uma 
forma de narração sobre o passado. Tomando como referência estas provocações lançadas por Robert Rosenstone é possível pensar o filme histórico como uma das formas de construção de histórias públicas. Assim, tirando o foco das análises propostas por Marc Ferro, e pensando o filme na perspectiva de Robert Rosenstone, filmes históricos podem ser vistos como possíveis histórias públicas na perspectiva daquelas produzidas fora do âmbito da atuação do historiador.

No entanto, um filme, como uma obra de arte coletiva, cujos múltiplos sentidos são construídos a partir da atuação de diversos sujeitos, nem sempre constrói uma narrativa sobre o passado à revelia dos historiadores se considerarmos as diversas experiências nas quais os historiadores atuam como consultores em diferentes aspectos do filme, inclusive, para a construção do roteiro ou argumento.

Fonseca (2016) demonstra, por exemplo, as relações entre a construção da biografia de Villa-Lobos no filme Villa-Lobos uma vida de paixão (Zelito Viana, 1997) a partir de um diálogo estreito com as biografias do músico, inclusive com as histórias fantasiosas que ele contava sobre si mesmo. No caso deste filme, o processo de pesquisa para o roteiro foi realizado por uma historiadora. Outros exemplos foram estudados por Fonseca (2008, 2017) demonstrando a relação estabelecida entre os filmes e as bases escritas sobre a temática que aborda, trazendo, ou não, questões historiográficas para dentro da dramaturgia do filme. Ao estudar, por exemplo, os filmes Independência ou morte (Carlos Coimbra, 1972) e Carlota Joaquina, a princesa do Brazil (Carla Camurati, 1995) demonstra como os filmes dialogam com as referências, historiográficas ou não, que pautaram as construções das situações dramáticas, personagens, cenários, etc. apontando para os diálogos existentes entre o filme e aquilo que lhe informava enquanto leitura do passado.

Desta forma, é possível demonstrar, através da abordagem proposta por Robert Rosenstone de considerar o filme como uma forma possível de escrita sobre o passado, que filmes históricos dialogam, com maior ou menor intensidade, com abordagens escritas anteriores ao filme, bem como com uma "história pública" sobre a temática enfocada figurando, desta maneira, em um contexto de elaboração de uma cultura histórica.

E, apesar de uma suposta oposição entre uma história produzida por "nós" historiadores e uma outra coisa sobre o passado produzida por "eles" não historiadores, 
dentre as quais podemos inserir as obras dos fotógrafos, jornalistas, romancistas, cineastas, compositores, atores, etc, todos estes compartilham de um "espaço" mais ou menos comum, no qual algumas referências sobre o passado circulam. Não de um lado para o outro, mas, de todos os lados para todos os lados, criando contaminações e imagens que formam uma espécie de "história pública" compartilhada. Historiadores influenciados por músicas, por filmes, por romances, por notícias, constroem suas visões de mundo, e, de passados, a partir desta sopa de referências que compõem universos de experiências.

\section{Considerações finais: Compartilhar fazeres na pesquisa para roteiros cinematográficos}

A partir da compreensão de que grande parte dos filmes com temáticas históricas trazem, em seu processo de produção, preocupações mínimas com referências historiográficas, Fonseca (2008) estudou o processo de roteirização cinematográfica e a relação estabelecida com pesquisas históricas tomando como referência as preocupações de Carlo Ginzburg (2002) que propôs, para as análises historiográficas, "deslocar a atenção do produto literário final para as fases preparatórias, para investigar a interação recíproca, no interior do processo de pesquisa, dos dados empíricos com os vínculos narrativos.” (p.114). Assim, guardadas as devidas proporções, demonstrou a preocupação na possibilidade, ou não, de uma interação, no processo de roteirização e pesquisa, entre a prática historiográfica desenvolvida pelos historiadores e a criação cinematográfica, com todas as suas especificidades, desenvolvida por roteiristas e diretores.

Ao propor debruçar-se sobre o processo criativo narrativo de um filme histórico, tendo a preocupação esmiuçar e compreender formas possíveis nos quais os filmes podem dialogar com os dados historiográficos, em seus processos de produção, pesquisa e roteirização (FONSECA, 2008) buscou compreender como diretores e roteiristas se relacionavam com as fontes históricas, construindo, assim, histórias visuais a partir de um lastro de conhecimento histórico, acadêmico ou popular. Desta forma, não era outra a preocupação senão considerar o filme como uma narrativa produtora de conhecimento sobre o passado com grande potencial de circulação e formação de ideias, que dialoga com histórias públicas de seu tempo. 
Reformulando, à luz de novos conceitos, dentre eles, de "história pública", essas preocupações ganham uma outra dimensão. O conceito de história pública se torna fundamental para justificar estas abordagens e estudos, principalmente no estabelecimento das diferenças entre a história produzida na academia e a produzida no cinema brasileiro, para, a partir daí construir possibilidades colaborativas entre esses dois espaços, conforme o conceito de "autoridade compartilhada" (Frisch, 2016).

Ao pensar em diferenças de maneira alguma a história produzida na universidade é pensada como superior à produzida no cinema. Por vários motivos, dentre eles, por serem produtos sociais e culturais de natureza e metodologias distintas, com tradições distintas. Pensar a diferença mirando na possibilidade colaborativa entre história e cinema significa um profundo respeito pelas soluções criativas nas tradições diferenciadas de ambas as áreas e a aceitação da negociação, que implica tanto no recuo quanto no avanço das ideias, em prol de ambas. E aqui uma utopia: os historiadores e a sociedade ganham com filmes sobre o passado brasileiro que instiguem, que façam refletir, que provoquem, que disseminem ideias complexas sobre o passado brasileiro, que sejam vistos pelo público. Cineastas ganham com novas ideias, novas narrativas, novas abordagens, novas possibilidades de roteiros, novos pontos de vistas que possam ser trazidas pelas pesquisas historiográficas. Essa interação pode ser muito mais instigante.

Concordando com Frisch, que defende que a história pública não seja uma via de mão única, propondo um "reimaginar e reorientar esta estrada rumo a um terreno público verdadeiramente inclusivo, contestado, aberto e dialógico" (FRISCH, 2016, p.61), partindo das experiências, ideias e práticas de diversos protagonistas na arte de criar histórias visuais para, à luz das referências da metodologia e do "modo de fazer" historiográfico, é possível propor reflexões e aproximações das duas áreas no âmbito do "fazer".

Um historiador, na produção de um filme, pode atuar como o intérprete desse "país distante" e, ao contrário do que se imagina, pode enriquecer a abordagem trabalhando em parceria com roteiristas e cineastas. No entanto, para que seja possível uma parceria é fundamental compreender as diferenças. Fonseca (2008) propôs observar e analisar a forma como as pesquisas foram feitas na elaboração de alguns filmes brasileiros com temáticas 
históricas, para, depois, juntamente com a análise desse processo, propor compartilhamentos possíveis.

A partir das diversas entrevistas com cineastas, montadores, roteiristas, atores e pesquisadores a autora identificou e classificou práticas e abordagens na relação estabelecida entre a produção cinematográfica, naquele momento, o processo de roteirização e a busca por informações históricas, chamada, genericamente de "pesquisa". Assim, propôs a seguinte classificação: a pesquisa pensada como levantamento de dados; a pesquisa e a construção da estrutura narrativa do filme; a pesquisa e a busca de elementos dramáticos e a pesquisa e construção do argumento do filme.

Essa classificação pode ser questionável e simplificadora do processo de roteirização e pesquisa, no entanto, a classificação propõe pensar em objetivos e possíveis pontos de diálogo entre um historiador e um roteirista. Por exemplo, existem diferenças entre uma pesquisa para embasar situações dramáticas de um roteiro original em elaboração, e, uma pesquisa para construção de argumentos de um filme, ou seja, para construção da espinha dorsal do filme. Assim, esses tipos de pesquisa para roteiros não estão, necessariamente, nesta ordem e nem claramente delineadas durante o processo e, nem sempre presente em todos os filmes. A divisão é apenas para compreender o processo, e como toda esquematização está sujeita a simplificações.

Poderíamos dizer que são quatro situações de pesquisa: uma primeira situação que pode ser identificada como uma pesquisa inicial ampla, que poderia ser chamada de levantamento de dados, na qual busca-se muito material sem um foco especifico. Uma outra situação, que seria uma espécie de pesquisa para construção da narrativa. As relações entre a pesquisa e a narrativa podem ser variadas: pode já existir a definição da linha narrativa do filme e essa pesquisa procura dar substância a ela; a linha narrativa pode ter sido descoberta a partir dessa pesquisa mais ampla ou ser um processo de construção concomitante. Uma terceira situação, uma espécie de pesquisa dramatúrgica, ou seja, a busca por elementos que alimentem a dramaturgia. Nesse ponto entra a pesquisa de personagens, a busca por conflitos, ações e emoções. A construção dramática não se limita às ficções, ela está presente também em documentários. E, por fim, a quarta situação que seria a construção de argumentos para filmes, a partir das referências documentais historiográficas. 
Pode um filme histórico ser considerado história pública? Considerando a possibilidade de filmes históricos construírem realidades e difundirem práticas e abordagens sobre o passado, sim, ele pode ser visto como história pública. Por outro lado, considerando como história pública aquela produzida pela mediação do historiador a partir do domínio de outras linguagens, então, se isto ocorrer no âmbito cinematográfico, então, sim, isso pode ser história pública. No entanto, a terceira possibilidade, que envolve a prática compartilhada, seria a atuação do historiador como um dos agentes criativos do processo de elaboração de um filme, que é uma obra de arte coletiva, a partir do desenvolvimento de pesquisas históricas na elaboração de roteiros.

\section{REFERÊNCIAS}

ALMEIDA, Juniele Rabêlo. Práticas de história pública: o movimento social e o trabalho de história oral. In: MAUAD, Ana Maria; ALMEIDA, Juniele Rabêlo de; SANTHIAGO, Ricardo (organizadores). História Pública no Brasil: Sentidos e itinerários. São Paulo: Letra e Voz, 2016. pp.47-56

CARVALHO, Bruno Leal Pastor de. Onde fica a autoridade do historiador no universo digital? In: MAUAD, Ana Maria, SANTHIAGO, Ricardo; BORGES, Viviane Trindade. Que história pública queremos? São Paulo: Letra e Voz, 2018. pp.169-174

FERREIRA, Marieta de Moraes. Quais as afinidades entre um mestrado profissional em ensino de história e a história pública? In: MAUAD, Ana Maria, SANTHIAGO, Ricardo; BORGES, Viviane Trindade. Que história pública queremos? São Paulo: Letra e Voz, 2018b. pp.49-58

FERREIRA, Rodrigo de Almeida. Qual relação entre a história pública e o ensino de História? in: MAUAD, Ana Maria, SANTHIAGO, Ricardo; BORGES, Viviane Trindade. Que história pública queremos? São Paulo: Letra e Voz, 2018. pp.29-38 FERRO, Marc. Cinema e História. Rio de Janeiro: Terra e Paz, 1992.

FONSECA, Vitória Azevedo da. A Monarquia no cinema brasileiro. Metodologia e análise de filmes históricos. Jundiaí: Paco Editorial, 2017 
FONSECA, Vitória Azevedo da. Pesquisa histórica e cinema: a criação de Villa-Lobos. ArtCultura_Revista de História, Cultura e Arte Uberlândia, v. 18, p. 99-110, 2017b. Disponível em: http://www.seer.ufu.br/index.php/artcultura/article/view/37951

FONSECA, Vitória Azevedo da. Cinema na história e a história no cinema: pesquisa e criação em três experiencias cinematográficas no Brasil dos anos 1990. Tese (Doutorado em História) Universidade Federal Fluminense, Niterói, 220p., 2008. Disponível em: https://www.historia.uff.br/stricto/teses/Tese-2008_FONSECA_Vitoria_Azevedo_da-S.pdf FRISCH, Michael. A história pública não é uma via de mão única, ou, de A Shared Authority à cozinha digital, e vice-versa. In: MAUAD, Ana Maria; ALMEIDA, Juniele Rabêlo de; SANTHIAGO, Ricardo (organizadores). História Pública no Brasil: Sentidos e itinerários. São Paulo: Letra e Voz, 2016. pp.57-70

GINZGURB, Carlo. Relações de Força. História, retórica, prova. São Paulo: Companhia das Letras, 2002.

HERMETO, Miriam. Podem os palcos ser lugares de história pública? In: MAUAD, Ana Maria, SANTHIAGO, Ricardo; BORGES, Viviane Trindade. Que história pública queremos? São Paulo: Letra e Voz, 2018. pp.153-160

KNAUSS, Paulo. Quais os desafios dos museus em face da história pública? In: MAUAD, Ana Maria, SANTHIAGO, Ricardo; BORGES, Viviane Trindade. Que história pública queremos? São Paulo: Letra e Voz, 2018. pp.141-146

MATTOS, Hebe; GRINBERG, Keila; ABREU, Martha. Que diferença faz a perspectiva da história pública nos estudos sobre a escravidão? In: MAUAD, Ana Maria, SANTHIAGO, Ricardo; BORGES, Viviane Trindade. Que história pública queremos? São Paulo: Letra e Voz, 2018. pp. 229-238

MAUAD, Ana Maria. Como as fotografias visualizam a história pública? In: MAUAD, Ana Maria, SANTHIAGO, Ricardo; BORGES, Viviane Trindade. Que história pública queremos? São Paulo: Letra e Voz, 2018. pp. 121-130.

MAUAD, Ana Maria; ALMEIDA, Juniele Rabêlo de; SANTHIAGO, Ricardo (organizadores). História Pública no Brasil: Sentidos e itinerários. São Paulo: Letra e Voz, 2016. 
MENESES, José Newton Coelho. Todo patrimônio é uma forma de história pública? MAUAD, Ana Maria, SANTHIAGO, Ricardo; BORGES, Viviane Trindade. Que história pública queremos? São Paulo: Letra e Voz, 2018b. pp. 69-76

MENESES, Sônia. Qual a função da história pública em um país caracterizado por uma forte concentração midiática? In: MAUAD, Ana Maria, SANTHIAGO, Ricardo; BORGES, Viviane Trindade. Que história pública queremos? São Paulo: Letra e Voz, 2018. pp.181188

RODRIGUES, Rogério Rosa. A história pública serve para a teoria da história, e vice-versa? In: MAUAD, Ana Maria, SANTHIAGO, Ricardo; BORGES, Viviane Trindade. Que história pública queremos? São Paulo: Letra e Voz, 2018. pp. 277-284

ROSENSTONE, Robert A. La pelicula historica como campo, como modo de pensamiento (historiar) y un montón de malas jugadas que les hacemos a los Muertos. in: MONTÓN, A,L.H., GOMEZ, G.C. Gómez Hacer historia con imágenes (coords). Editorial Síntesis. Madrid, 2014.

SCHITTINO, Renata. O conceito de público e o compartilhamento da história. in: MAUAD, Ana Maria; ALMEIDA, Juniele Rabêlo de; SANTHIAGO, Ricardo (organizadores). História Pública no Brasil: Sentidos e itinerários. São Paulo: Letra e Voz, 2016. pp.37-46 SCHMIDT, Benito Bisso. Qual a relação entre história pública e a profissionalização do historiador? In: MAUAD, Ana Maria, SANTHIAGO, Ricardo; BORGES, Viviane Trindade. Que história pública queremos? São Paulo: Letra e Voz, 2018. pp.17-28 